\title{
Students' Interest in Understanding Geometry in South African High Schools
}

\author{
Dikeledi Mamiala $^{1}$, Andile Mji ${ }^{1}$, Sibongile Simelane-Mnisi ${ }^{2, *}$ \\ ${ }^{1}$ Department of Mathematics, Science \& Business Education, Faculty of Humanities, Tshwane University of Technology, Pretoria, \\ South Africa \\ ${ }^{2}$ Higher Education Development \& Support, Department of Curriculum Development \& Support: ELearning, Tshwane University of \\ Technology, Pretoria, South Africa
}

Received August 11, 2020; Revised November 13, 2020; Accepted November 29, 2020

\section{Cite This Paper in the following Citation Styles}

(a): [1] Dikeledi Mamiala, Andile Mji, Sibongile Simelane-Mnisi, "Students' Interest in Understanding Geometry in South African High Schools," Universal Journal of Educational Research, Vol. 9, No. 3, pp. 487-496, 2021. DOI: 10.13189/ujer.2021.090308.

(b): Dikeledi Mamiala, Andile Mji, Sibongile Simelane-Mnisi (2021). Students' Interest in Understanding Geometry in South African High Schools. Universal Journal of Educational Research, 9(3), 487-496. DOI: 10.13189/ujer.2021.090308.

Copyright $\bigcirc 2021$ by authors, all rights reserved. Authors agree that this article remains permanently open access under the terms of the Creative Commons Attribution License 4.0 International License

Abstract The major contributors of challenges with teaching and learning of Euclidean Geometry relate to teaching pedagogy, teaching methodologies, students' lack of interest in Geometry, lack of understanding of many geometric concepts and lack of use of technology. The performance of students in high school Geometry, Grade $10-12$, is poor. Students with high self-efficacy that is linked to interest, are more likely to make efforts to complete a task and persist longer in those efforts. The purpose of this paper was to investigate students' interest in understanding Geometry in high school Further Education and Training phase. Participants were 390 Grade 10-12 Mathematics students from Mpumalanga and North West in South Africa. A mixed-methods approach was utilized following the convergent parallel sequential design. Qualitative data were collected through the survey questionnaire, with open-ended and closed-ended questions to determine students' interest in Geometry. Atlas ti was used to analyse qualitative data. The quantitative aspects were analysed with SPSS. It was found that students indicated that the teachers continue to teach even if they do not understand. The results also showed that more than half $(57.1 \%)$ of the students felt calm and relaxed when they were attempting Geometry problems. About $60 \%$ of the students were confident enough to take Mathematics at high school level, which included Geometry. It is recommended that teachers take into consideration the students' interests when planning and preparing Geometry lessons.

Keywords Geometry, Students' Interest, Student Self-efficacy, High School

\section{Introduction}

Geometry at high school Further Education and Training level is regarded as more complex, even though it appears less abstract than the rest of Mathematics to teach and learn [1]. In this case, it has resulted in poor performance amongst the students [2,3]. Poor performance in Geometry may be because students regard it as very difficult to learn [4]. Smith, Julie and Gierdien [5] argued that the main aims of Geometry are the development of thinking abilities of spatial intuition about the world, knowledge necessary to study more Mathematics, as well as the ability to interpret mathematical arguments. Geometry is the bedrock of engineering and technological development [1]. In South Africa, Geometry is part of Mathematics, and includes about $30 \%$ of the final National Curriculum Statement Grade 12 paper [1].

The major contributors of challenges with teaching and learning of Euclidean Geometry relate to teachers' pedagogy, teaching methodologies, students' lack of 
interest in Geometry, lack of understanding of many geometric concepts and lack of use of technology [7,8]. The research revealed that students' poor performance could be linked to various factors relating to a poor foundation of basic knowledge from their primary stage, lack of willingness and readiness to learn Geometry, lack of a deeper understanding, lack of properly trained teachers, and an imbalanced teacher-learner ratio [9]. Other authors identified lack of physical models in the TIMSS, Pisa examinations, students' inability to solve problems and answer Geometry questions, and students lacked an understanding of three dimensions $[10,11]$. To add to this list, Ngirishi[8] identified students' lack of understanding of many Geometric concepts, understanding definitions of Geometry terms, identification of interrelationships of properties and shapes, as well as the lack of procedural and conceptual understanding.

The purpose of this study was to investigate students' interest in understanding Geometry in high school Further Education and Training (FTE) phase. Firstly, to determine student interests, a Geometry Students Self-Efficacy questionnaire was administered. Secondly, an open-ended questionnaire, developed by the authors, was used to establish the views of the students on the teaching and learning of Geometry.

\subsection{Student Interest in Geometry}

Interest has been identified as one of the elements that play a pivotal role in enhancing students' self-efficacy in learning Geometry [12]. This author argues that student engagement, teacher flexibility and homework frequency positively influenced students' interest in the subject [12]. It pointed out that students' interest in Geometry is encouraged by motivation $[13,14]$. The motivation was found to be one of the key features that were closely related to interest, and as such, it is essential to focus on how it relates to and enhance self-efficacy in Geometry $[15,16]$. Kandil and Ișıksal-Bostan[17] pointed out that when students feel their teachers like them, they tend to experience greater school engagement and perform better academically. On the other hand, it is argued that in Taiwan students have a lower interest in learning Mathematics particularly low-achieving students [18].

High self-efficacy may affect motivation in both positive and negative ways [19]. Although interest as part of affection is viewed as an essential element of the learning process, research has shown that it has not been given the attention it deserves in learning and teaching $[20,21]$. Interest in the subject is one of the commonly known affection constructs viewed to be critical in student's learning and achievement in Geometry [22], although interest was found to be an appropriate indicator of problem-solving ability rather than prior experience with Geometry [23]. [24] argue that interest is essential for successful student learning.

\subsection{Student Self-efficacy}

In general, students with high self-efficacy that is linked to interest are more likely to make a task, and tend to persist longer in those efforts than those with low self-efficacy [25]. The stronger the self-efficacy or mastery expectations are, the more active the efforts will be. However, students with low self-efficacy sometimes expect incentives to learn Geometry. If they do not perform, they put blame on the teachers of not being able to explain a particular concept, whereas those with a high self-efficacy will put more effort into completing any given task [13]. In this case, Sudihartinih and Wahyudin[26] argue that there is a relationship between self-efficacy and the level of geometric thinking, yet it is weak.

\section{Materials and Methods}

The question posed in this study is: How interested are students in the teaching and learning of Geometry? To answer the research question, a convergent parallel sequential design within the mixed methods approach was employed. Mixed methods research has the intentional integration of the qualitative and quantitative approach to best addressing the research problem [27], hence its application in this study. Convergent parallel sequential design means that both the quantitative and quantitative data were collected simultaneously between October-November 2015. The analysis was carried out separately using appropriate analysis techniques for quantitative and qualitative [28]. In this study, qualitative data were collected through the survey questionnaire with open-ended questions to better understand the views of students' regarding the teaching and learning of Geometry. On the other hand, quantitative data were collected using a Geometry Students Self-Efficacy questionnaire (GSS-EQ) to determine students' interest in Geometry. Quantitative data were analysed using SPSS frequency distribution and percentage. For qualitative data, Atlas.ti was used. A hermeneutic unit named Geometry FET Project, was created. One primary document was uploaded which comprised of three open-ended questions. From these documents, 177 codes were highlighted and grouped into three conceptual networks.

\subsection{Participants}

Participants in this study were 390 Grade 10-12 Mathematics students from South Africa in Mpumalanga and North West Province. Purposeful and convenience sampling were used to select the participants. Purposeful sampling provides the opportunity for in-depth investigation in research [29,30]. Convenience sampling is described in terms of choice of settings, groups and or individuals that are conveniently available and willing to 
participate in the study [31]. There were $231(59.2 \%)$ students from Mpumalanga, and 159 (40.8\%) students from North West. It may be seen from Table 1 that the majority, $236(60.5 \%)$ of the students were women. Their ages range between 15 years and 23 years. More pleasing was the fact that $86.4 \%$ indicated that they definitely wanted to study further. In terms of careers, about half indicated that they wanted to be in Information Technology. This was followed by Chartered Accountant (17\%), Medical Doctor (13\%) and Lawyer (12\%). It should be pointed out that five students did not respond to the question related to future career choice. Table 1 shows biographical data of the students according to interest in studying further, taking Mathematics as measured by following Mathematics-related courses.

Table 1. Biographical data of the students $(\mathrm{N}=390)$

\begin{tabular}{|c|c|c|}
\hline Category & $\mathrm{N}$ & $\%$ \\
\hline \multicolumn{3}{|l|}{ Gender } \\
\hline Women & 236 & 60.5 \\
\hline Men & 154 & 39.5 \\
\hline \multicolumn{3}{|l|}{ Age } \\
\hline $15-17$ & 109 & 27.9 \\
\hline $18-19$ & 233 & 59.7 \\
\hline $20+$ & 48 & 12.4 \\
\hline \multicolumn{3}{|c|}{ Study further } \\
\hline Definitely & 337 & 86.4 \\
\hline Maybe & 48 & 12.3 \\
\hline No & 5 & 1.3 \\
\hline \multicolumn{3}{|l|}{ Career } \\
\hline Information Technology & 190 & 50.1 \\
\hline Chartered Accountant & 66 & 17.1 \\
\hline Medical Doctor & 50 & 13.0 \\
\hline Communication Specialist & 16 & 4.2 \\
\hline Human Resource Manager & 5 & 1.3 \\
\hline Police & 4 & 1.0 \\
\hline Auditor & 3 & .8 \\
\hline Engineering & 1 & .3 \\
\hline
\end{tabular}

\subsection{Instruments and Procedure}

The GSS-EQ and open-ended questionnaire were used to collect data. GSS-EQ comprised of five constructs that include: How competent a student feels about Geometry; How anxious a student is about Geometry; How interested a student is in Geometry; The importance of Geometry to a student; and: How comfortable or at ease a student is with Geometry. For the purpose of this paper, student interest in Geometry was used. The students' interest in Geometry construct had ten items. The internal consistency alpha value for this item was found to be .81 . The alpha values were adjudged to be good, based on the guidelines for clinical significance of fair if $.70 \leq \alpha<.80$; good if $.80 \leq \alpha<.90$; and $\geq .90$ excellent [32]. Students were requested to respond to item statements by registering their choices on a Likert-type scale. Here, the purpose was to investigate students' interest in Geometry in high school FET. Students had to rate their responses in a Likert-type scale ranging from 1 = Definitely False, to 6 $=$ Definitely True. Some of the typical statements from students' interests were:

- In dealing with Geometry problems, I feel comfortable.

- I feel calm and relaxed when I am attempting Geometry problems.

- I am quite good at Geometry.

The open-ended questionnaire comprised of three questions. These questions assisted the researchers to understand Geometry teaching and learning, and the impact of students' interest in the subject. The open-ended questions were developed by the authors. It comprised of three questions. The typical questions students had to respond to were:

- How they view their teachers' way of teaching Geometry in class.

- How do you become actively involved during Geometry lessons?

- What do you like most about your Geometry lessons?

\section{Results}

The results are presented according to the ten items of the GSS-EQ that were used to answer the question: How interested students are in teaching and learning of Geometry? Table 2 shows the results in respect of 10 items from the construct: How is students' interest in Geometry. In terms of item 1, I will work as long as necessary to solve a difficult Geometry problem, it may be observed that more than half $(55.7 \%)$ experienced challenges in solving difficult Geometry problems. The students revealed definitely false, to more false than true. This implies that more than half of the students find Geometry to be one of the difficult Mathematics concepts, and this leads to low self-efficacy. Concerning item 2, I have usually been at ease and relaxed during a Geometry test or examination, the results show that more than half $(51.6 \%)$ of students felt that they were not at ease and relaxed during a Geometry test or examination. The students indicated that more false than true, to more true than false. This means that Geometry was complicated and not easy to understand which makes them tense during tests and examinations. Concerning item 3, in dealing with Geometry problems, I feel comfortable, more than half $(51.7 \%)$ of the students felt comfortable when dealing with Geometry problems. The students revealed truer, to more true than false to this item. This implies that 
students were at ease and comfortable with the manner Geometry was taught. In terms of item 4, I feel calm and relaxed when I am attempting Geometry problems, it may be seen that more than half $(57.1 \%)$ of the students felt calm and relaxed when attempting Geometry problems. The students indicated more true than false, to definitely true. This suggests that more than half of the students attempted Geometry with a positive attitude, as they felt relaxed and calm in their ability to solve the theorems. About item 5, I am comfortable having to do Geometry, the results show that more than half $54.8 \%$ ) of the students were not comfortable in having to do Geometry. This suggests that students felt uneasy and confused in solving Geometry problems, as well as taking part in Geometry activities within the classroom. This means that most of the students felt that Geometry was complicated and not easy for them to understand.

According to item 6, The thought of taking high school Geometry does not scare me, the results revealed that more than half $(60 \%)$ of the students indicated more true than false, to definitely true to this question. This suggests that more than half of the students were confident enough to take Mathematics at high school level, which included Geometry. This later could benefit them in Science- and Engineering courses at tertiary level. In terms of item 7, I have generally done better in Mathematics compared to other subjects, it may be observed from the results that 227 students indicated definitely false, to more false than true. This implies that more than half $(58.2 \%)$ of the students struggled with Mathematics; compared with other subjects. This may suggest that students' lack of interest in Geometry could have affected their performance in Mathematics. With regard to item $8, I$ am quite good at Geometry, the results show that $51.6 \%$ of the students indicated definitely false, to more false than true. This suggests that more than half of the students are not good at Geometry, which indicated that their level of interest in Geometry is low. Concerning item 9, I have trouble understanding anything that is based upon Geometry, the results show that more than half (55.9\%) of the students have trouble understanding anything that was based upon Geometry. This suggests that students are experiencing problems and have difficulty in understanding Geometry. In terms of item 10, I always do well in tests that require mathematical reasoning, more than half $(57.5 \%)$ of the students did not do well in tests requiring mathematical reasoning. Students revealed definitely false, to more false than true. This suggests that more than half of the students perform poorly to tests that require mathematical reasoning, especially in Geometry.

Table 2. Students' interest in Geometry

\begin{tabular}{clcccccc}
\hline \multicolumn{1}{c}{ Category } & $\begin{array}{c}\text { Definitely } \\
\text { False }\end{array}$ & False & $\begin{array}{c}\text { More False } \\
\text { than True }\end{array}$ & $\begin{array}{c}\text { More True } \\
\text { than False }\end{array}$ & $\begin{array}{c}\text { True } \\
\text { Definitely } \\
\text { True }\end{array}$ \\
\hline 1 & $\begin{array}{l}\text { I will work as long as necessary to } \\
\text { solve a difficult Geometry problem }\end{array}$ & $111(28.5)$ & $106(27.2)$ & $54(13.8)$ & $33(8.5)$ & $50(12.8)$ & $36(9.2)$ \\
& $\begin{array}{l}\text { I have usually been at ease and } \\
\text { relaxed during a Geometry test or } \\
\text { examination }\end{array}$ & $60(15.4)$ & $81(20.8)$ & $60(15.4)$ & $52(13.3)$ & $84(21.5)$ & $53(13.6)$ \\
3 & $\begin{array}{l}\text { In dealing with Geometry problems, I } \\
\text { feel comfortable }\end{array}$ & $46(11.8)$ & $61(15.6)$ & $81(20.8)$ & $50(12.8)$ & $107(27.4)$ & $45(11.5)$ \\
4 & $\begin{array}{l}\text { I feel calm and relaxed when I am } \\
\text { attempting Geometry problems }\end{array}$ & $45(11.5)$ & $59(15.1)$ & $63(16.2)$ & $52(13.3)$ & $100(25.6)$ & $71(18.2)$ \\
5 & $\begin{array}{l}\text { I am comfortable having to do } \\
\text { Geometry }\end{array}$ & $75(19.2)$ & $91 .(23.3)$ & $48(12.3)$ & $48(12.3)$ & $82(21.0)$ & $46(11.8)$ \\
6 & $\begin{array}{l}\text { The thought of taking high school } \\
\text { Geometry does not scare me }\end{array}$ & $59(15.1)$ & $66(16.9)$ & $31(7.9)$ & $48(12.3)$ & $104(26.7)$ & $82(21.0)$ \\
7 & $\begin{array}{l}\text { I have generally done better in } \\
\text { Mathematics compared to other } \\
\text { subjects }\end{array}$ & $62(15.9)$ & $88(22.6)$ & $77(19.7)$ & $61(15.6)$ & $68(17.4)$ & $34(8.7)$ \\
8 & $\begin{array}{l}\text { I am quite good at Geometry } \\
\text { I have trouble understanding anything } \\
\text { that is based upon Geometry. }\end{array}$ & $60(15.4)$ & $81(20.8)$ & $60(15.4)$ & $52(13.3)$ & $84(21.5)$ & $53(13.6)$ \\
10 & $\begin{array}{l}\text { I always do well in tests that require } \\
\text { mathematical reasoning }\end{array}$ & $58(14.9)$ & $92(23.6)$ & $74(19.0)$ & $61(15.6)$ & $58(14.9)$ & $47(12.1)$ \\
\hline
\end{tabular}




\subsection{Open-ended Questionnaire}

The open-ended questionnaire was used for the in-depth understanding of the main research question: How interested students are in teaching and learning of Geometry? This questionnaire assesses Geometry teaching and learning with an aim to understand students' interest, comprising of 3 questions. The open-ended questions were completed and returned by all participants; 390 students. In some instances, students did not disclose certain information that was asked in the open-ended questionnaire. In Question 1, students were required to provide information on how they view their teachers' way of teaching Geometry in class. About 64 codes emerged from the primary document. These codes were grouped into eight categories related to the theme of students' views on Geometry teachers' teachings. Students indicated that the teachers continued to teach even if they do not understand. In most cases, it seems as if teachers were rushing to finish the syllabus so that the students could start with revision. Motshabi said: "Well, at the same point it feels like she is rushing just to finish the syllabus to revise. Sometimes we do not understand the work, so it is difficult for us to revise on our own". Most students preferred using the previous Grade 12 Mathematics question papers for revising, as they were able to solve more relevant examination questions. Lebogang echoed: "The teacher gives us question paper and help us as we do some problems". Most students showed a positive attitude towards the teachers' teachings. They pointed out that their teachers' way of teaching enabled them to understand Geometry very well. Gugulethu said: "She is the best, she understood her thoroughly, she explains until they understand". Students saw the need for using extra resources in their learning that could help them to understand the given activities. Monty said: "She is a very good teacher; she solves some of the problems, provide examples and tries to make each student understand". She uses extra resources to help them, but sometimes she (Monty) just fails to understand.

In Question 2, students were required to provide information about their active involvement in a Geometry lesson. Here, 61 codes emerged from the primary document. These codes were grouped into three themes. The themes were active Geometry participation, partially active and inactive participation. Figure 1 shows the conceptual network relating to students' involvement in Geometry. From active Geometry participation, students revealed their active involvement in doing Geometry exercises. It allowed them to ask the teacher to elaborate or explain more on the concept where they could not understand. Lesego said he tries to cooperate by answering questions and by asking where he does not understand. Thogo mentioned: To practice every day, to ask when he does not understand and to work with other students together. The main reason for the majority of students to become actively involved in a lesson was to get the answers correct. Mpho highlighted that she gets actively involved by getting the answers right or correct. Regarding partially active, these students needed other students to trigger their minds before they could be actively involved. Lesiba said he sometimes asks his deskmate if he knows something, then in that way, he becomes involved. Other students indicated that they preferred to share their ideas with their peers, comparing their answers to the given problem. Lebo revealed that she compares her findings with those that she is sitting with, and if she is wrong, she seeks help. Inactive participation referred to the students who did not participate, and who were passive in the lesson. Most of the students gave different reasons for not participating at all. Moeketsi indicated that he lacks confidence and even get lost. He is not sure if it is him or he does not understand the topic. Thembi stated that she does not become involved even though she tries; she just gets lost and gives up the whole thing. At times she feels like she does not deserve to be in class. Some of the inactive students felt that the teacher is neglecting them during the lesson without helping. 


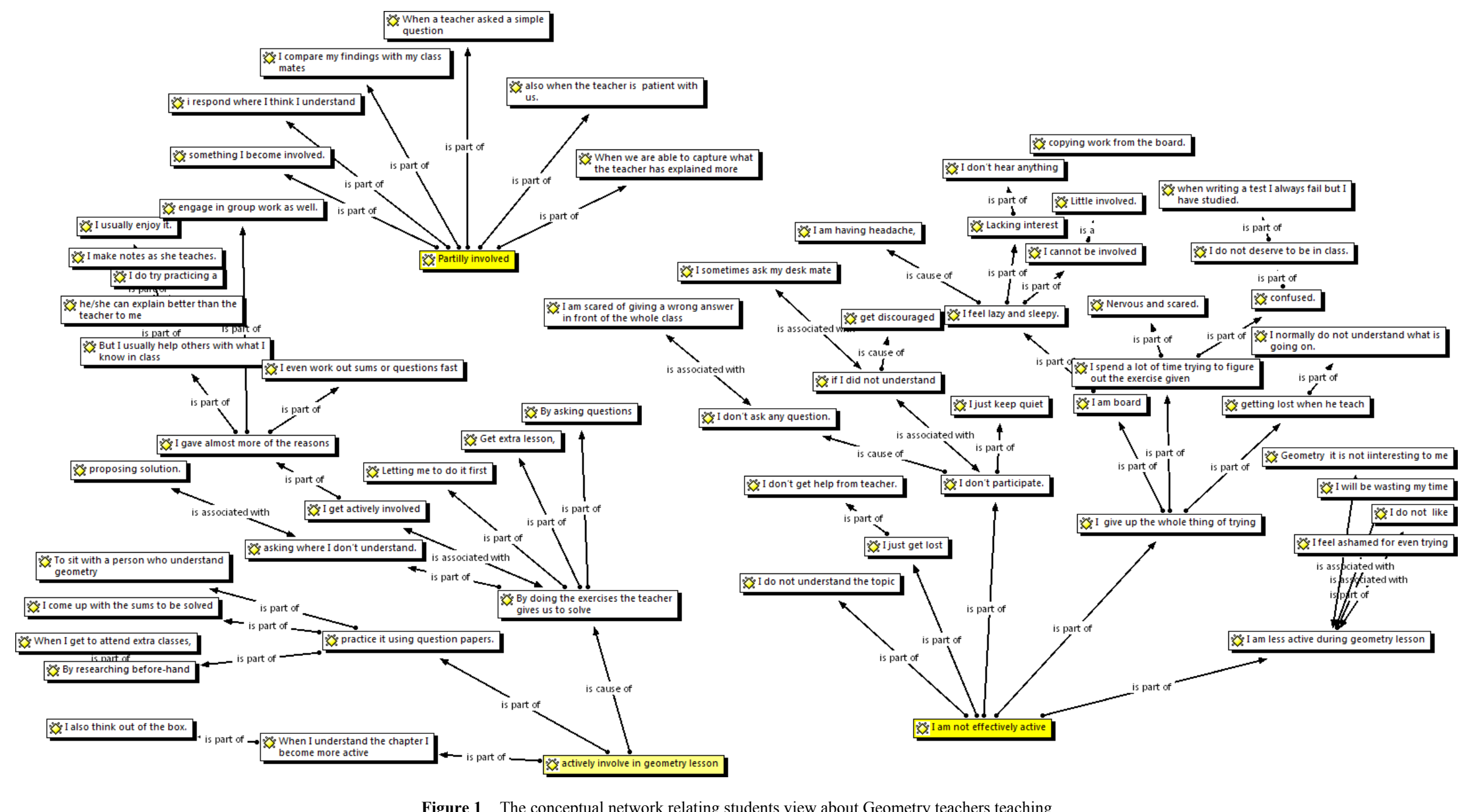

Figure 1. The conceptual network relating students view about Geometry teachers teaching 
Dipuo indicated she is not participating at all. Sometimes she sleeps during the lesson. She wants to be involved, but she does not get help from the teacher.

In Question 3, students were required to provide information on what they like about the Geometry lesson. In this instance, 52 codes emerged from the primary document. These codes were grouped into seven categories related to the theme what students like about Geometry. Students indicated that, since they all know that Geometry was a challenge, they realised that there was a need for them to work hard. Mathe said: "Geometry is challenging, so it makes one wants to work hard". To overcome the challenging situation about Geometry, students revealed that doing more class activity would help them. Lobisa indicated that the part where one cannot understand, one has to do more activities. Students revealed that they felt good in getting the solution correct when solving problems. This also helped them to construct new knowledge about new Geometry vocabulary they were not familiar with. Puseletso mentioned that, getting the solution correctly in every Geometry lesson leaves you with a new vocabulary. Students revealed that the kind of motivation they received from their teachers encourages them to be interested in learning Geometry. Boitumelo mentioned that "the teacher motivates us while learning", and that makes her have more interest in learning Geometry. They also indicated that teachers' detailed explanations gave in class, encouraged them to be more confident in solving more challenging problems. Sara mentioned that, once a teacher gets deeper into details she understands, and when she answers correctly in class, she gets confidence and practices more to always be correct. This also encouraged the students to be actively involved in any class activities. They came up with their own ideas and constructed new ideas. Mampuru said: "It makes you think out of the box and to be focused in order to get it right".

\section{Discussion}

The purpose of this study was to answer the following question: How interested are students in the teaching and learning of Geometry? To answer this question, qualitative and quantitative methods were used. Before providing the answers it is worth mentioning that the reliability of the scores from the GSS-EQ construct used in this study was found to be good and acceptable. It was found in this study that more than half of the students interpreted Geometry to be one of the more difficult Mathematics concepts that lead to low self-efficacy. Also, students revealed that Geometry was complicated and not easy to understand, which makes them tense during tests and examinations. Rahay and Sugianto [33] support this view. They argued that Geometry is one mathematical concept that is both challenging and abstract. It was also found that more than half of the students in this study were not comfortable to do Geometry. They felt uneasy and confused when taking part in Geometry activities, and in solving Geometry problems. Uneasiness and confusion of students in Mathematics are also reported in [34]. Furthermore, [35] reported that students who were less creative in responding to Geometry problems does not like learning mathematics, and were afraid.

It was also found that about $58.2 \%$ of the students struggled with Mathematics in comparison with other subjects. It may be argued that the lack of interest in Geometry could has affected their performance in Mathematics. In this case, it was reported that more than half of students were not good in Geometry, and had trouble in understanding anything based upon Geometry. As the result of lack of interest and confidence indicated, approximately $57.5 \%$ of the students did not do well in tests requiring mathematical reasoning. Their performance was low in Mathematics, especially in Geometry concepts. It may be observed from the findings that students were frustrated and disappointed with their poor performance in test results. Mamali [36] reported this sentiment, and indicated that the attitude of students towards learning Geometry is very poor. Furthermore, [35] indicated that students with less Mathematics or Geometry concepts stored in the memory, felt uncomfortable and unhappy while studying the subject. Because of the low interest in Geometry, it was critical in this study to understand students' views about their teachers' way of teaching Geometry in class. It was determined that students found it difficult to understand their teachers. In this case, students felt teachers continued to teach, even if they did not understand, and they rushed to complete the syllabus. Msibi and Oloyede [37] also raised concerns about teachers rushing through the syllabus. It could be argued that teachers need to be sensitive and aware of their pace and arrangement of teaching activities that may enhance teaching for understanding, as it may lead to increased student interest in Geometry.

Even though students experienced challenges with Geometry in this study, more than half (51.7\%) mentioned that they were at ease and comfortable with the manner in which Geometry was taught. These students attempted Geometry with a positive attitude as they were relaxed and calm in their ability to solve the theorems. This was supported by their views that they showed a positive attitude towards their teachers' teachings. This is observed in [38], who argued that it is critical for teachers to make a plan and implement comfortable learning to students when conveying their ideas. Students pointed out that their teachers' way of teaching enabled them to understand Geometry very well. They indicated that their teachers were able to teach them until they could understand. Furthermore, it was also found that these students were confident enough to take Geometry in high 
school. It pointed out that, when students showed interest in Geometry, their achievement, emotions and academic performance tended to increase [39]. It was also found that in terms of careers; about $50 \%$ of the students indicated they wanted to pursue careers in Information Technology, becoming Chartered Accountants and Medical Doctors.

To learn more about students' interest, it was also important in this study to learn more about their active involvement in Geometry lessons. In this case, students indicated that Geometry exercises allowed them to ask the teacher to elaborate or explain more on concepts they did not understand. It was also found that these students needed other students to activate their thinking before they could be actively engaged in Geometry classes. It may be argued that students engage and work collaboratively to learn from one another. Active participation was promoted through heterogeneous group activities where students actively engaged, discussed and supported each other to solve Geometry problems [40]. It was also reported that other students in this study were not actively involved in Geometry classes. They were not participating at all, and lack general interest in Geometry. This result is supported by [41], who revealed that a minority of students in their study did not exhibit any interest in studying Geometry, and assumed a passive role in the classroom.

Concerning what students liked about Geometry, it was found in this study that students needed to work hard because they found Geometry challenging. This was also noted by $[42,43]$, when they investigated the problem-based type of activities within classroom environment. Furthermore, students indicated that engaging in more class activities would help them. It was also found that students were able to construct new knowledge when solving Geometry problems on their own. Constructivist promotes this, where the emphasis is based on students' ability to understand, construct and solve problems on their own [44]. It may be observed that students were motivated when teachers encouraged them and commented positively; they were more interested in learning Geometry. It may also be argued in this study that students had high self-efficacy. Students with high self-efficacy are more likely to make efforts to complete a task [25,45]. This is also supported by [35], who mentioned that students who applied the creative category of Bloom's taxonomy in solving Mathematics and Geometry concepts, tend to have excellent and complete schemata in formal, content and linguistic schemata.

\section{Conclusions}

It may be concluded in this study that, after many years of research in Mathematics and Geometry, it is still indeed a very difficult subject and concept to learn. Challenges in learning Geometry contribute to the poor performance of students. Students' lack of interest and understanding of
Geometry was found to be massive in this study. Factors contributing to a lack of interest were that Geometry is generally believed to be a difficult Mathematics concept, as it is complicated and not easy to understand. Students do not feel comfortable in their ability to do it. They regard themselves as being sub-par, as they have trouble in understanding the geometric concepts. These factors lead to poor performance in Geometry. Despite the concern raised related to students' interest, we argued that the majority still perceive Mathematics as being important, and acknowledge its relevance. This is one of the factors that need to be taken into consideration if performance in Geometry is to be improved, and self-efficacy is to be enhanced. Geometric artefacts surround every-day experiences, and as such, the teaching of Geometry needs to include such geometrical objects; if interest in Geometry teaching is to be sustained at the school level. Active participation was reportedly playing a major role in cultivating interest. Therefore, this aspect also needs to be considered interest is to be developed and maintained in Geometry learning. Students still perceived Mathematics as important, and acknowledge its relevance in their planned careers.

\section{Recommendations}

During the development of a framework on professional development programmes (PDP), aspects that influence interest need to be taken into consideration if sustainable learning in Geometry is to be maintained. Students' interests must be considered when teachers plan and prepare Geometry lessons. It is recommended that indigenous or local knowledge and Afrocentric be included in the teaching of Geometry to make it easy for the students to start from the known to abstract knowledge of Geometry. Recognition of this important element may contribute to sustainable learning in Geometry at the school level. Ethno-Mathematics approaches must be used in teaching Geometry, as Geometry and culture are interrelated.

\section{REFERENCES}

[1] A. Giannakopoulos. An Alternative Way of Solving Geometry Riders in Grade 12: Back Toto Synthesis and Analysis, Proceedings of the 23rd Annual National Congress of the Association for Mathematics Education of South Africa, Port Elizabeth, 2, 3-7, 2017.

[2] G. Sunzuma, A. Maharaj. In-service teachers' geometry content knowledge: Implications for how geometry is taught in teacher training institutions, International Electronic Journal of Mathematics Education, Vol.14, No.3, 633-646, 2019. 
[3] T. Uygun. An inquiry-based design research for teaching geometric transformations by developing mathematical practices in dynamic geometry environment, Mathematics Education Research Journal, 2020.

[4] N. Bikić, S. M. Maričić, M. Pikula. The effects of differentiation of content in problem-solving in learning geometry in secondary school, Eurasia Journal of Mathematics, Science \& Technology Education, Vol.12, No.11, 2783-2795, 2016.

[5] C. R. Smith, C. Julie, F. Gierdien. The integration of semiotic resources and modalities in the teaching of geometry in a grade 9 class in a South African high school: The four cases of congruency. South African Journal of Education, Vol.40, No.2, 2020.

[6] S. Van Putten, S. Howie, G. Stols. Making Euclidean geometry compulsory: Are we prepared? Perspectives in Education, Vol.28, No.4, 22-31, 2010.

[7] N. P. Dinayusadewi, G. N. S. Agustika. Development of augmented reality application as a mathematics learning media in elementary school geometry materi. Journal of Education Technology. Vol.4, No.2, 204-210, 2020.

[8] H. Ngirishi. Exploration of FET mathematics learners' and understanding of geometry, Masters' thesis, University of KwaZulu Natal, Durban, South Africa, 2015.

[9] Y. L. Tsao. The effect of constructivist instructional-based mathematics course on the attitude toward Geometry of pre-service. US-China Education Review, Vol.1 No.8, 1-10, 2018 .

[10] H. Gür, M. Kobak-Demir. Geometry teaching via origami: The views of secondary mathematics teacher trainees. Journal of Education and Practice, Vol.8, No.15, 65-71, 2017.

[11] J. Naidoo, W. Kapofu. Exploring female learners' perceptions of learning geometry in mathematics. South African Journal of Education, Vol.40, No1, 2020

[12] C. W. Johnson (SR). The link between teacher practices and high school students' Mathematics self-efficacy: A multilevel analysis, Doctoral thesis, Cleveland State University. 2008.

[13] R. D. Liu, R. Zhen, Y. Ding, Y. Liu, J. Wang, R. Jiang, L. Xu. Teacher support and math engagement: Roles of academic self-efficacy and positive emotions. Educational Psychology, Vol.38, No.1, 3-16, 2018.

[14] F. Rahmawati, M. D. Pamungkas, R. Sariningtias. The Van Hiele Geometry Thinking Level Of Autism Students. Advances In Social Science, Education and Humanities Research, Vol.397, 3rd International Conference on Learning Innovation and Quality Education (ICLIQE) 2019.

[15] T. Laurens, F. A. Batlolona, J. R. Batlolona, M. Leasa. How does realistic mathematics education (RME) improve students' mathematics cognitive achievement? EURASIA Journal of Mathematics, Science and Technology Education, Vol.14, No.2, 569-578, 2018.

[16] R. Sulfiyah, Baiduri, A. D. Ismail. Analysis of student's conceptual understanding on visualization phase in learning geometry by using spinning wheel media. Mathematics Education Journals, Vol.3, No.2, 2019
[17] S. Kandil, M. Işıksal-Bostan. Effect of inquiry-based instruction enriched with origami activities on achievement, and self-efficacy in geometry, International Journal of Mathematical Education in Science and Technology, Vol.50, No.4, 557-576, 2019.

[18] C. Y. C. Yen, H. N. H. Cheng, Z. H. Chen, C. C. Y. Liao, T. W. Chan. Enhancing achievement and interest in mathematics learning through math-island, Research and Practice in Technology Enhanced Learning, Vol.14, No.1, 2019.

[19] W. Kassis, U. Graf, R. Keller, K. Ding, C. Rohlfs. The role of received social support and self-efficacy for the satisfaction of basic psychological needs in teacher education. European Journal of Teacher Education, Vol.42, No.3, 391-409. 2019.

[20] N. Fitriani. P. Nurfauziah. Gender and mathematical abstraction on geometry, Journal of Physics: Conference Series. 1315 012052. International Seminar on Applied Mathematics and Mathematics Education, 2019.

[21] S. Schukajlow, K. Rakoczy, R. Pekrun. Emotions and motivation in Mathematics education: Theoretical considerations and empirical contributions. ZDM Mathematics Education, Vol.49, No.3, 307-322, 2017.

[22] M. Pantziara. Student self-efficacy beliefs. In. Goldin, G. A. Hannula, M. S. Heyd-Metzuyanim, E. Jansen, A. Kaasila, R. Lutovac, S. DiMartino, P. Morselli, F. Middleton, J. A. Pantziara, M. Zhang (Eds.), Attitudes, beliefs, motivation, and identity in Mathematics education, Heidelberg, Springer, 2016.

[23] S. Schukajlow, K. Achmetli, K. Rakoczy. Does constructing multiple solutions for real-world problems affect self-efficacy? Educational Studies in Mathematics, Vol.100, No.1, 43-60, 2019.

[24] R. Lazarides, H. Gaspard, A. L. Dick. Dynamics of classroom motivation: Teacher enthusiasm and the development of math interest and teacher support, Learning and Instruction, Vol.60, 126-137, 2019.

[25] G. S. Mason, T. R. Shuman, K. E. Cook. Comparing the effectiveness of an inverted classroom to a traditional classroom in an upper-division engineering course, Education, IEEE Transactions, Vol.56, No.4, 430-435, 2013.

[26] E. Sudihartinih, W. Wahyudin. Pembelajaran berbasis digital: studi penggunaan geogebra berbantuan e-learning untuk meningkatkan hasil belajar matematika, Jurnal Tatsqif, Vol.17, No.1, 87-103, 2019.

[27] J. H. Hitchcock, A. J. Onwuegbuzie, Developing mixed methods crossover analysis approaches, Journal of Mixed Methods Research, Vol.14, No.1, 1-20, 2019.

[28] V. Plano-Clark, N. Ivankova. Mixed Methods Research: A Guide To The Field, Thousand Oaks, CA, Sage, 2016.

[29] S. Mnisi. Exploring a teaching strategy using clicker mobile technology for active learning in undergraduate Mathematics classes, Doctoral theses, Tshwane University of Technology, Pretoria, South Africa, 2015.

[30] C. J. White. Research: A Practical Guide. Pretoria, South Africa, Ithuthuko Investment Publishing, 2005. 
[31] H. Collins. Creative Research: The Theory and Practice of Research for the Creative Industries (Required Reading Range), Design Management (1), AVA, Switzerland, 2010.

[32] D. V. Cicchetti. Guidelines, criteria, and rules of thumb for evaluating normed and standardized assessment instruments in psychology, Psychological Assessment, Vol6, No.4, 284-290, 1994.

[33] R. Rahayu, M. Sugianto. Mathematics teaching using generative learning model with character building content aided by interactive learning media, Journal of Mathematics Education Research, Vol.8, No.1 35-48, 2019.

[34] D. E. Murphy. A phenomenological study of college students in developmental mathematics classes experiences with mathematics and computer anxiety, Doctoral thesis, Liberty University, Lynchburg, VA 2018.

[35] Wahyudi, S. B. Waluya, H. Suyitno, Isnarto, S. M. Pramusita1. Schemata in creative thinking to solve mathematical problems about Geometry, Universal Journal of Educational Research, Vol.7, No.11 2444-2448, 2019.

[36] N. R. Mamali. Enhancement of learners' performance in geometry at secondary schools in the Vhembe district of the Limpopo province. Master thesis, University of Venda, South Africa, 2015.

[37] T. N. Msibi, O. I. Oloyede. Examining the use of higherorder thinking questions on prose, International Journal of Social, Politics \& Humanities, Vol.1, No.4, 135-141, 2019.

[38] S. Utami, B. Usodo, I. Pramudya. Level Of Students' Creative Thinking In Solid Geometry, The 2nd Annual International Conference on Mathematics and Science Education Phys, Journal of Physics, Conf. Series, 1227,
2019.

[39] R. Pekrun, S. Lichtenfeld, H. W. Marsh, R. Murayama, T. Goetz. Achievement emotions and academic performance: Longitudinal models of reciprocal effects, Child Development, Vol.5 No.88, 1653-1670, 2017.

[40] D. G. Denbel. Functions in the secondary school mathematics curriculum. Journal of Education and Practice, Vol6, No.1, 77-81, 2019.

[41] D. Vegara, M. L. Fernández, M. Lorenzo. Enhancing student motivation in secondary school mathematics courses: A methodological approach. Educational Science, Vol.83, $1-11,2019$.

[42] E. M. Schoevers, P. P. M. Leseman, E. M. Slot, A. Bakker, R. Keijzer, E. H. Kroesbergen. Promoting pupils' creative thinking in primary school mathematics: A case study, Thinking Skills and Creativity, Vol31, 323-334, 2019.

[43] R. S. A. Said, X. Du, H. A. H. M. Alkhatib, M. H. Romanowski, A. I. I. Barham. Math teachers' beliefs, practices, and belief change in implementing problem based learning in Qatari primary governmental school, EURASIA Journal of Mathematics, Science and Technology Education, Vol.15, No.5, 1710, 2019.

[44] K. S. Taber. Constructivism as educational theory: Contingency in learning, and optimally guided instruction. In J. Hassaskhah (Ed.), Educational theory, New York, Nova, 39-61, 2011.

[45] F. Erdogan. Prospective middle school mathematics teachers' problem posing abilities in context of Van Hiele levels of geometric thinking, International Online Journal of Educational Sciences, Vol.12, No.2, 132-152, 2020. 